\title{
ORTHOSTATIC HYPOTENSION AND THE RENIN-ANGIOTENSIN SYSTEM IN PARAPLEGIA
}

\author{
By R. H. Johnson, D. M. Park and H. L. Frankel \\ University Department of Neurology, Institute of Neurological Sciences, Southern General \\ Hospital, Glasgow S.W.I \\ National Spinal Injuries Centre, Stoke Mandeville Hospital, \\ Aylesbury, Buckinghamshire
}

Patients with high spinal cord transection may suffer from orthostatic hypotension because of interruption of the normal baroreceptor reflex controlling blood vessels. The reflex depends upon carotid and aortic arch baroreceptors, which are innervated by the glossopharyngeal and vagal nerves respectively, medullary centres, and efferent autonomic pathways in the spinal cord. Patients with lesions above T6 are prone to suffer from symptoms of orthostatic hypotension (Guttmann, Munro, Robinson \& Walsh, I963). After the initial peroid of mobilisation, these patients are able to sit without symptoms for as long as they wish to do so. This suggests that circulatory adaptation to loss of the baroreceptor reflexes has developed and a possible mechanism is the development of reflex control of blood pressure at a spinal level. Animal experiments have implied that there is a form of reflex circulatory regulation at a spinal cord level (Beacham \& Kunze, I969; Andrews, Andrews \& Orbach, I97I) and some circulatory reflexes pass through the isolated spinal cord in man (Guttmann \& Whitteridge, I947; Gilliatt, I948; Gilliatt, Guttmann \& Whitteridge, I948; Corbett, Frankel \& Harris, I97I $a, b)$. Reflex homeostatic regulation of blood pressure, however, has not been demonstrated to occur in spinal man. Another possibility is that there may be a return of vascular tone (Sharpey-Schafer, I96I) which might be due to an increase in absolute levels of, or of sensitivities to, circulating humoral agents.

It has been shown that these patients have low levels of circulating catecholamines and that these are unaffected by change of posture (Guttmann, Munro, Robinson \& Walsh, 1963). Johnson, Smith and Spalding (I969) observed that when patients with cervical spinal cord transection were subjected to repeated changes in posture between the horizontal and the foot-down position over 20-30 min. there resulted a progressive reduction in orthostatic hypotension and elevation of the supine blood pressure (fig. I). Increases in blood pressure during a series of changes of posture have also been observed in patients with orthostatic hypotension in association with other disorders including cerebrovascular disease (Johnson, Smith, Spalding \& Wollner, 1965) and Holmes-Adie syndrome (Johnson, McLellan \& Love, I97I; Love, Brown, Chinn, Johnson, Lever, Park \& Robertson, I97I). Johnson et al. (I969) showed that this did not depend upon changes in blood volume and suggested that this phenomenon could be due to release of angiotensin which depends upon activation of the renin-angiotensin system.

Renin is an enzyme released from the kidney which acts on angiotensinogen, present in the plasma, to form angiotensin I, a decapeptide which in turn is converted to an octapeptide, angiotensin II (Brown, Lever \& Robertson, I968). This substance has a powerful vasoconstrictor effect on blood vessels and also stimulates the release of aldosterone from the adrenal cortex. The mechanisms controlling 


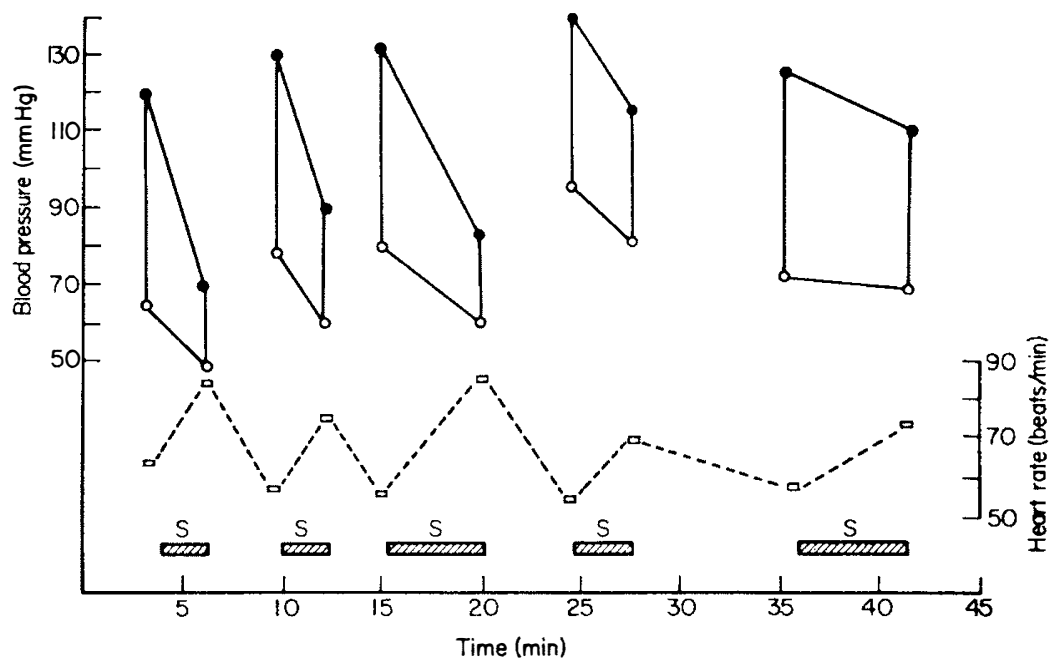

FIG. I

Effect of a series of changes of posture from horizontal to vertical in $40 \mathrm{~min}$. on blood pressure and heart rate of a patient with cervical cord transection $\left(\mathrm{C}_{7-8}\right)$ : there is a progressive rise of supine blood pressure and improvement of orthostatic hypotension. ( $\mathrm{S}=$ standing.) (From Johnson, Smith and Spalding (I969), Clin. Sci., by kind permission.)

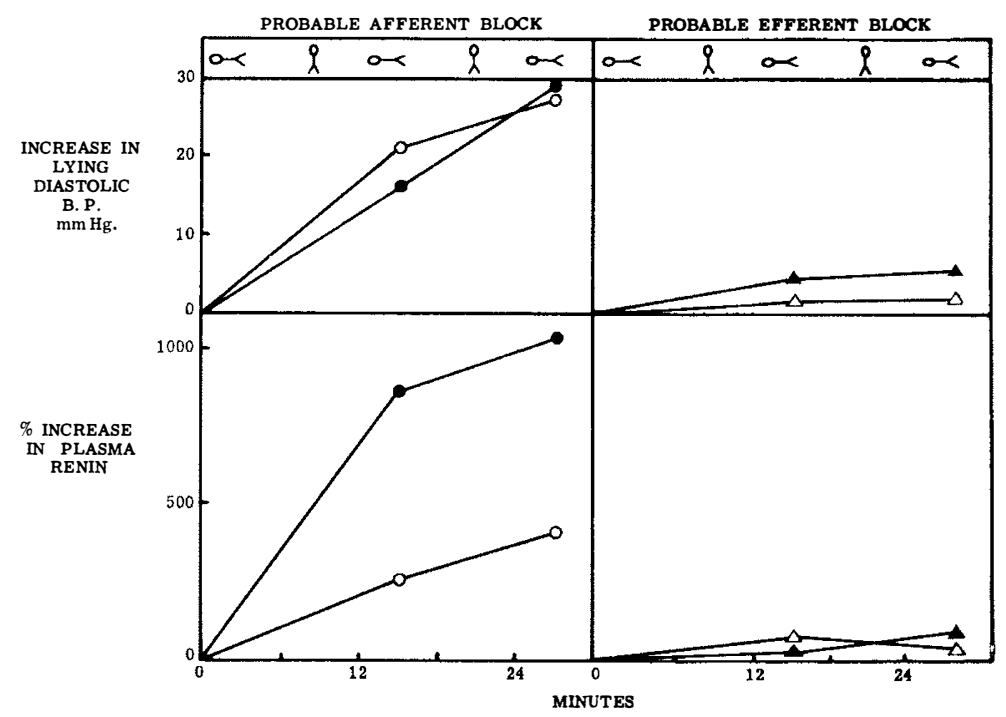

FIG. 2

Effect of changes of posture from horizontal to vertical on supine diastolic blood pressure and plasma renin in four patients with orthostatic hypotension: there was a progressive rise of supine diastolic blood pressure and plasma renin concentration in two subjects with afferent block from baroreceptors and negligible change in two subjects with efferent sympathetic block. This suggests that sympathetic fibres are involved in renin release. (From Love, Brown, Chinn, Johnson, Lever, Park and Robertson (1971), Clin. Sci., by kind permission. 
the release of renin are not fully understood but may depend at least in part upon the sympathetic nervous system (Davis, I97I).

Evidence for the Role of Efferent Sympathetic Nervous Pathways in the Release of Renin. We have investigated four patients with idiopathic orthostatic hypotension in whom two of the patients had evidence of a different physiological basis for their abnormality compared with the other two. Two patients had evidence of a block of the baroreceptor reflex on the efferent side, probably in postganglionic sympathetic nerves. Evidence included reduction of sweating and absent blood pressure responses to noise and mental arithmetic. There was also hypersensitivity of the blood pressure to infusion (i.v.) of noradrenaline and of the bladder to the cholinergic drug, carbachol. The other two patients who also had features of the Holmes-Adie syndrome, probably had a block of the baroreceptor reflex on the afferent side, because they had normal responses to these tests of efferent sympathetic pathway function. Measurements of plasma renin concentration (P.R.C.) were made in all patients when submitted to several changes of posture from the horizontal to the vertical in $30 \mathrm{~min}$. The two patients with the afferent baroreceptor block showed a progressive rise of supine blood pressure, and the P.R.C. also rose, the correlation being statistically significant. There was, however, no significant change in either blood pressure or P.R.C. in the patients with an efferent sympathetic block (fig. 2; Love et al., 197I). We concluded that the rapid changes in blood pressure provoked by change of posture may depend upon the activation of the renin-angiotensin system and that efferent sympathetic pathways, at least in part, are important for the release of renin in man.

The Action of Angiotensin in Spinal Man. The vasoconstrictor activity of angiotensin may be mediated by a direct effect on the brain stem within the territory supplied by the basilar artery (fig. 3; Scroop \& Whelan, 1966; Ueda, Uchida, Ueda, Gondaira \& Katayama, I969; Ferrario, Dickinson \& McCubbin, I970; Joy \& Lowe, I970; Scroop, Katic, Joy \& Lowe, I97I).

Angiotensin also has a peripheral action and paraplegics with lesions above the sympathetic outflow would depend solely upon this part of its activity. We have examined the action of angiotensin in patients with cervical cord transection and a dose, within the physiological range, is adequate to restore the blood pressure in a patient placed in the foot-down position in whom orthostatic hypotension was present (fig. 4).

Indirect evidence for increased activity of the renin-angiotensin system may be suggested by the observation that paraplegics with cervical cord transection have raised levels of aldosterone (Claus-Walker, Carter, Lipscomb \& Vallbona, I969). This could result in an increase in the circulating blood volume which could also be a compensation for loss of normal baroreceptor control of capacitance vessels. An increase in blood volume could also be mediated by release of antidiuretic hormone and this is known to occur with change of posture (Auger, Zehr, Siekert \& Segar, 1970).

Renin Release in Spinal Cord Transection. We are at present investigating the role of the renin-angiotensin system in patients with paraplegia. Our subjects have included patients with both high and low levels of injury and our studies have also been related to the duration of their disability and extent of mobilisation. Patients with cervical cord transection often have high levels of P.R.C. at rest and change of 


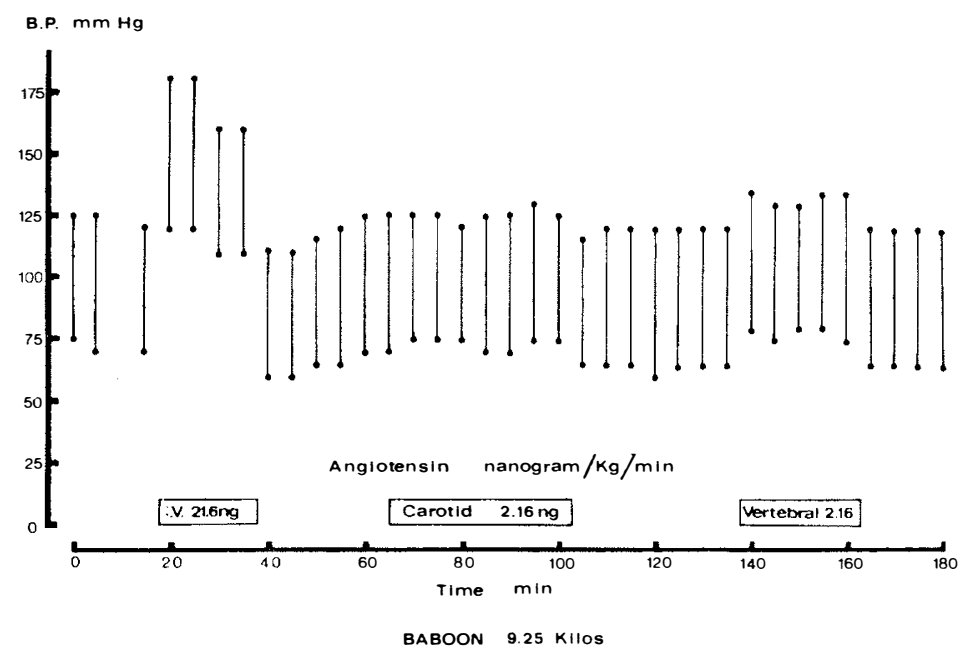

FIG. 3

Effect of infusions of angiotensin upon the arterial blood pressure of a baboon: there was a marked pressor response with intravenous infusion $(2 \mathrm{I} \cdot 6 \mathrm{ng} . / \mathrm{kg} . / \mathrm{min}$.$) , and at one-tenth dose, a$ negligible response from intracarotid infusion. The same dose by intravertebral infusion caused a definite pressor response.

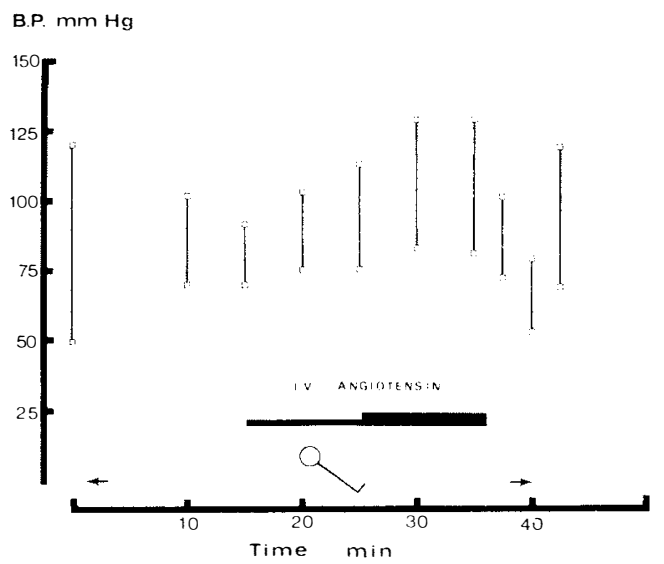

FIG. 4

Effect of infusion of angiotensin (i.v.) upon the blood pressure of a patient with cervical cord transection (C4-5): the infusion abolished the fall of blood pressure produced by change of posture to $45^{\circ}$, head up. (The horizontal bar indicates two different infusion rates.)

posture from the horizontal to the foot-down position results in an increase in P.R.C. well above the normal range. On return to the supine position the blood pressure is elevated and this appears to be related to P.R.C. (fig. 5). Some of the patients nevertheless still have symptomatic orthostatic hypotension in spite of the elevation of P.R.C., suggesting that activation of the renin-angiotensin system is insufficient alone to maintain blood pressure. Patients with lesions below the mid-thoracic 

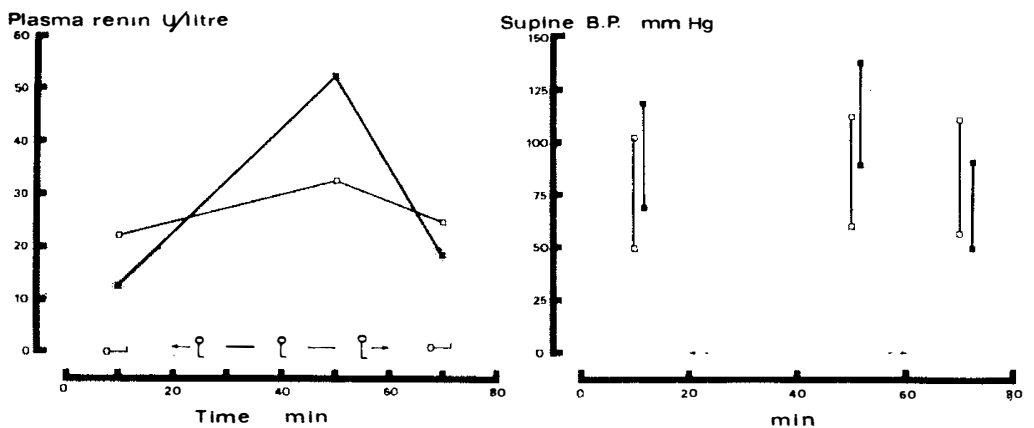

FIG. 5

Effect of changes of posture from the horizontal to the vertical (as indicated above the horizontal axis) upon plasma renin concentration (normal range $=4-20 \mathrm{U} /$ litre) and supine blood pressure of two patients with cervical spinal cord transection (C5-6, C6-7): there was a rise of supine blood pressure and a rise of plasma renin; one patient had high resting levels of plasma renin concentration.
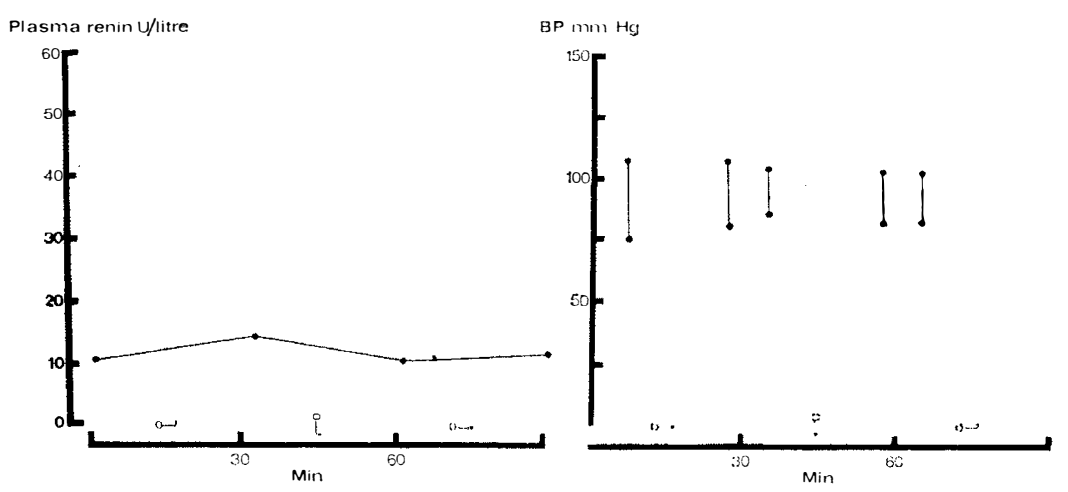

A

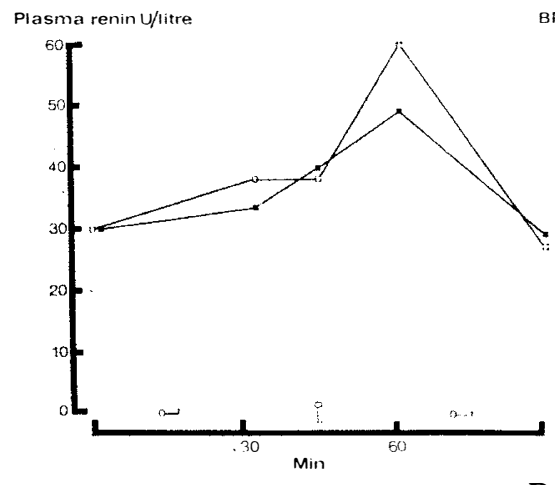

$B P(m+1) H G$

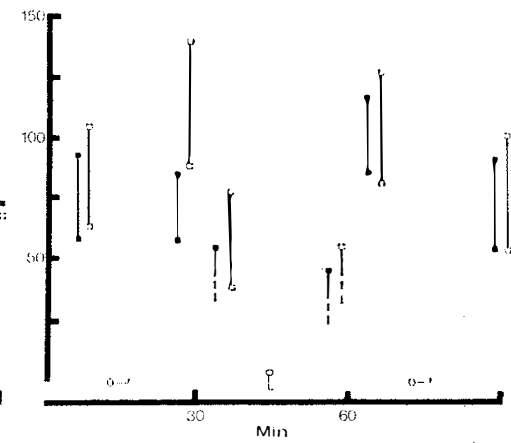

B

FIG. 6

Effect of sitting for $30 \mathrm{~min}$. after 12 hours recumbency on blood pressure and plasma renin concentration in spinal man. (a) A negligible change of renin concentration and blood pressure in a patient with T8 cord transection. (b) Marked postural hypotension in two patients with cervical cord transection, with high resting plasma renin concentration and marked rise during change of posture; there was also an elevated supine blood pressure after sitting. (An isolated period of hypertension in one patient at $25 \mathrm{~min}$. was related to bladder emptying.) 
level rarely suffer from orthostatic hypotension, and in these patients P.R.C. is within the normal range (fig. 6).

Observations of P.R.C. in patients with orthostatic hypotension due to other neurological disorders have produced conflicting evidence for the role of the sympathetic nervous system in renin release. It has been suggested that an integrated sympathetic nervous system is necessary (Gordon, Küchel, Liddle \& Island, I967; Chokroverty, Barron, Katz, Del Greco \& Sharp, I969) but our present observations fail to support this view.

Corbett, Frankel and Harris (I97Ic) have investigated the cardiovascular responses to change of posture in tetraplegic man and considered that any blood pressure overshoot they observed immediately after return to the supine position was associated with a spasm of skeletal muscles. They also frequently found that the blood pressure tended to overshoot the original resting value in the few minutes following tilting. They considered it possible that bladder distension produced both the progressive rise in resting blood pressure and improved response during tilting reported by Johnson, Smith and Spalding (1969).

Our observations provide evidence, however, that the renin-angiotensin system can be activated in spite of high cord transection. The high resting plasma renin concentrations in some of these patients suggest a compensatory role of the renin-angiotensin system to their orthostatic hypotension. The unusually high levels of P.R.C. obtained on change of posture suggest that some of the postural blood pressure responses of paraplegics could be due to angiotensin.

\section{SUMMARY}

Blood pressure has been studied in patients with orthostatic hypotension of several causes, including high spinal cord transection. Observations have included heart rate, the effect of angiotensin infusion, and measurement of plasma renin concentration intermittently throughout the investigation. Evidence is presented that a rise of blood pressure and also of plasma renin concentration may occur if sympathetic fibres are active. Release may, however, depend upon spinal sympathetic activity as change of posture can induce an elevation of plasma renin concentration in patients with high spinal cord transection. Such patients may have high resting values of plasma renin and the renin response to change of posture may play a part in the response to repeated change of posture for a few minutes and also in the chronic vascular adaptation which chronic paraplegics achieve.

Acknowledgments. We thank the patients who acted as subjects in these investigations. Plasma renin estimations were performed by the M.R.C. Blood Pressure Research Unit, Western Infirmary, Glasgow (Director, Dr. A. F. Lever), and we are most grateful for their continued interest and help. Professor J. A. Simpson has given encouragement and Dr. E. H. Jellinek, our colleagues at the Institute of Neurological Sciences, Glasgow, and at the Spinal Injuries Centre, Stoke Mandeville have kindly referred patients for investigation.

\section{REFERENCES}

Andrews, C. J. H., ANDrews, W. H. H. \& OrbaCh, J. (I97I). A spinal autonomic reflex evoked by congestion of the mesenteric vein. F. Physiol. (Lond.), 213, 37-38P.

Auger, R. G., Zehr, J. E., Siekert, R. G. \& Segar, W. E. (1970). Position effect of antidiuretic hormone. Arch. Neurol. 23, 513-517.

BeAChaM, W. S. \& KunZe, D. L. (I969). Renal receptors evoking a spinal vasomotor reflex. F. Physiol. (Lond.), 201, 73-85. 
Brown, J. J., Lever, A. F. \& Robertson, J. I. S. (I968). Hypotension. In Recent Advances in Medicine (Eds. Baron, D. N., Compston, N. and Dawson, A. M.), pp. 274-305. J. \& A. Churchill.

Chokroverty, S., Barron, K. D., Katz, F. H., del Greco, F. \& Sharp, T. J. (I969). The syndrome of primary orthostatic hypotension. Brain, 92, 743-768.

Claus-Walker, J. I., Carter, R. E., Lipscomb, H. S. \& Vallbona, C. (I969). Daily rhythms of electrolytes and aldosterone excretion in men with cervical spinal cord section. F. Clin. Endocrin. 29, 300-301.

Corbett, J. L., Frankel, H. L. \& HARris, P. J. (I97I $a$ ). Cardiovascular changes associated with skeletal muscle spasm in tetraplegic man. F. Physiol. (Lond.), 215, 381-393.

CoRBetT, J. L., Frankel, H. L. \& HARRIS, P. J. (I97I $b$ ). Cardiovascular reflex responses to cutaneous and visceral stimuli in spinal man. F. Physiol. (Lond.), 215, 395-409.

Corbett, J. L., Frankel, H. L. \& HarRis, P. J. (I97I $c$ ). Cardiovascular responses to tilting in tetraplegic man. F. Physiol. (Lond.), 215, 4I I-43I.

Davis, J. O. (I97I). What signals the kidney to release renin? Circulation Research, 28, $301-306$.

Ferrario, C. M., Dickinson, C. J. \& McCubBin, J.W.(I970). Central vasomotor stimulation by angiotensin. Clin. Sci. 39, 239-245.

Gilliatt, R. W., Guttmann, L. \& WhitTERIDGe, D. (1948). Inspiratory vasoconstriction in patients after spinal injuries. F. Physiol. (Lond.), 107, 67-75.

Gilliatt, R. W. (1948). Vasoconstriction in the fingers after deep inspiration. F. Physiol. (Lond.), 107, 76-88.

GoRdon, R.D., KÜCHEL, O., LidDLE, G. W. \& IsLAND, D. P. (1967). Role of the sympathetic nervous system in regulating renin and aldosterone production in man. F. Clin. Invest. 48, 599-605.

GuttmanN, L. \& Whitteridge, D. (1947). Effect of bladder distension on autonomic mechanisms after spinal cord injuries. Brain 70, 36I-404.

Guttmann, L., Munro, A. F., Robinson, R. \& Walsh, J. J. (1963). Effect of tilting on the cardiovascular responses and plasma catecholamine levels in spinal man. Paraplegia, I, 4-I8.

Johnson, R. H., McLellan, D. L. \& Love, D. R. (I97I). Orthostatic hypotension and the Holmes-Aide Syndrome: A study of two patients with afferent baroreceptor block. F. Neurol. Neurosurg. Psychiat. (in press).

Johnson, R. H., Smith, A. C., Spalding, J. M. K. \& Wollner, L. (1965). Effect of posture on blood pressure in elderly patients. Lancet, $\mathbf{r}, 73 \mathrm{I}-733$.

Johnson, R. H., Smith, A. C. \& Spalding, J. M. K. (I969). Blood pressure responses to standing and Valsalva's manoeuvre: independence of the two mechanisms in neurological diseases including cervical cord lesions. Clin. Sci. 36, 77-86.

Joy, M. D. \& Lowe, R. D. (1970). The site of cardiovascular action of angiotensin II in the brain. Clin. Sci. 39, 327-336.

Love, D. R., Brown, J. J., Chinn, R. H., Johnson, R. H., Lever, A. F., Park, D. M. \& ROBERTSON, J. I. S. (I97I). Plasma renin concentration in idiopathic orthostatic hypotension: differential response in subjects with probable afferent and efferent autonomic failure. Clin. Sci. (in press).

Scroop, G. C. \& WhELAN, R. F. (I966). A central vasomotor action of angiotensin in man. Clin. Sci. 30, 79-90.

Scroop, G. C., Katic, F., Joy, M. D. \& Lowe, R. D. (I97I). Importance of central vasomotor effects in angiotensin-induced hypertension. Brit. Med. F. i, 324-326.

Sharpey-SCHAFER, E. P. (I96I). Venous tone. Brit. Med. F. ii, I589-I595.

Ueda, H., Uchida Y., Ueda, K., Gondaira, T. \& Katayama, S. (I969). Centrally mediated vasopressor effect of angiotensin II in man. Fapanese Heart f. 10, 243-247. 